\title{
A video depicting resuscitation did not impact upon patients' decision-making
}

This article was published in the following Dove Press journal: International Journal of General Medicine

\author{
Caitlin Richardson-Royer \\ Imran Naqvi' \\ Christopher Riffel' \\ Lawrence Harvey' \\ Domonique Smith' \\ Dagmawe Ayalew' \\ Nasim Motayar' \\ Yaw Amoateng-Adjepong ${ }^{1,2}$ \\ Constantine A Manthous ${ }^{3}$ \\ 'The Jewish Hospital of Cincinnati, \\ Cincinnati, OH, USA; ${ }^{2}$ Yale University \\ School of Medicine, New Haven, CT, \\ USA; ${ }^{3}$ Lawrence \& Memorial Hospital, \\ New London, CT, USA
}

Correspondence: Constantine A

Manthous

6 Hemingway Road, Niantic, CT 06357, USA

Tel +I 2039092089

Email constantinemanthous@gmail.com

\begin{abstract}
Background: Previous studies have demonstrated that video of and scripted information about cardiopulmonary resuscitation (CPR) can be deployed during clinician-patient end-of-life discussions. Few studies, however, examine whether video adds to verbal information-sharing. We hypothesized that video augments script-only decision-making.
\end{abstract}

Methods: Patients aged $>65$ years admitted to hospital wards were randomized to receive evidence-based information ("script") vs. script plus video of simulated CPR and intubation. Patients' decisions registered in the hospital record, by hospital discharge were compared for the two groups.

Results: Fifty script-only intervention patients averaging 77.7 years were compared to 50 script+video patients with a mean age of 74.7 years. Eleven of $50(22 \%)$ in each group declined CPR; and an additional three (script) vs. four (script+video) refused intubation for respiratory failure. There were no differences in sex, self-reported health trajectory, functional limitations, length of stay, or mortality associated with decisions.

Conclusion: The rate at which verbally informed hospitalized elders opted out of resuscitation was not impacted by adding a video depiction of CPR.

Keywords: end of life, cardiopulmonary resuscitation, CPR, intubation, mechanical ventilation, autonomy

\section{Introduction}

When considering hypothetical scenarios that describe risks, benefits, and alternatives, a majority of elders prefer not to receive cardiopulmonary resuscitation (CPR) or endotracheal intubation/mechanical ventilation. ${ }^{1}$ Since informed consent is not required for these invasive procedures in the US, CPR and intubation are frequently provided by default ${ }^{2}$ despite ample opportunity to discern patients' wishes before CPR.

Accordingly, investigators have tested methods to enhance patient decision-making regarding CPR. Studies have suggested that brief, narrated videos depicting CPR and intubation, deployed during verbal information-sharing, impact decisions of cancer patients, ${ }^{3,4}$ critically ill surrogates, ${ }^{5}$ and acutely hospitalized elders nearing end-oflife. ${ }^{6}$ We hypothesized that video depicting CPR/intubation would impact decisions of non-critically ill, hospitalized elders who receive uniform information regarding risks, benefits, and alternatives of resuscitation.

\section{Methods}

This protocol (NCT01878968) was approved by the Institutional Review Board of the Jewish Hospital of Cincinnati, a 350-bed community teaching hospital, where the 
study was performed. Patients were candidates for the studies if they were $>65$ years and admitted to the department of medicine hospitalist service. Each morning, a list of patients admitted to the service in the prior 24 hours was generated using the hospital's electronic medical records. Patients were excluded if they had been admitted or transferred to/from the critical care unit, if they required contact isolation or if they already had a formal order precluding CPR or intubation. Eligible patients were approached for participation by study personnel and included if they provided verbal and formal written consent.

Patients who agreed to participate (Figure 1) were randomized to hear a brief, evidence-based script (Figure S1) with or without viewing a video depicting simulated CPR and mechanical ventilation (Video S1). The formal recorded resuscitation decisions, at discharge, of study patients and those who refused participation were the primary outcome of interest.

Demographic, self-reported functional status and health trajectory, resuscitation decisions, and outcomes of the index hospitalization (including intensive care unit transfer, intubation, CPR, mortality, and length of stay) were recorded for all study patients. Outcomes of patients receiving script alone were compared to those of script+video and to non-participants by Z-test for proportions, non-paired Student's $t$-tests, and analysis of variance as appropriate. Multiple logistic regression analyses were used to adjust for confounding, and included mechanistically plausible independent variables and those found to differ between groups' univariate analyses. A $P$-value of $<0.05$ signified statistical significance.

\section{Results}

Fourteen hundred sixty-four patients were assessed for eligibility between September and December 2014; 1281 did not meet entry criteria, 83 refused, and 100 agreed to participate. This cohort included 53 women and 47 men,

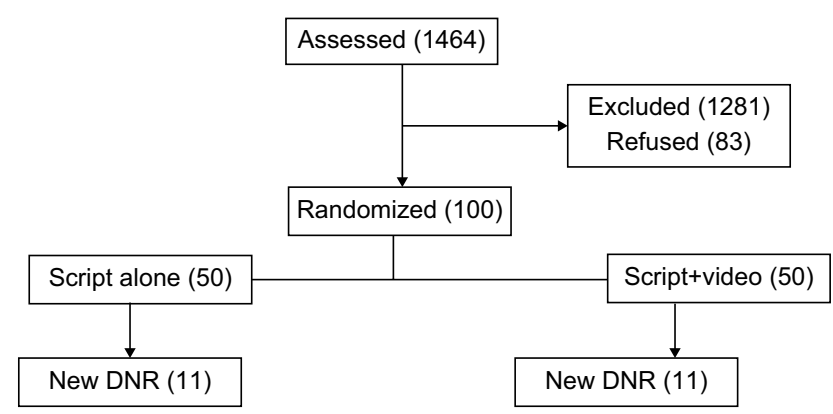

Figure I CONSORT figure for patient entry $(\mathrm{DNR}=$ no CPR and/or endotracheal intubation).

Abbreviations: DNR, do not resuscitate; CPR, cardiopulmonary resuscitation.
73 Whites, 25 African-Americans, and one Hispanic. The average length of stay was 4.4 days. All patients reported their pre-study understanding of resuscitation prognosis, activities of daily living, instrumental activities of daily living, and 6-month health trajectory (Table 1). Fifty-six $(56 \%)$ reported no change in their health 6-12 months prior to admission, 18 (18\%) reported worsening, and $26(26 \%)$ reported improving. Thirty-one patients $(31 \%)$ believed that $\geq 50 \%$ of patients survive hospitalization after CPR. Thirty (30\%) believed that $70 \%$ of patients requiring mechanical ventilation were alive 1 year later.

Fifty patients who received the script-only intervention averaging 77.7 years were compared to 50 patients with average age 75.7 years, randomized to script+video. There were no differences in sex, self-reported 6-month health

Table I Characteristics and resuscitation decisions of patients randomized to script alone vs. script+video

\begin{tabular}{|c|c|c|}
\hline Criteria & $\begin{array}{l}\text { Script } \\
(n=50)\end{array}$ & $\begin{array}{l}\text { Script+video } \\
(n=50)\end{array}$ \\
\hline Age (SD), years & $77.7(7.1)$ & $74.7(6.6)$ \\
\hline Men & 22 & 25 \\
\hline Women & 28 & 25 \\
\hline White* & 43 & 30 \\
\hline Black* & 7 & 19 \\
\hline Asian & 0 & 0 \\
\hline Hispanic & 0 & 1 \\
\hline Advanced degree & 14 & 6 \\
\hline College degree & 10 & 9 \\
\hline Some college & 16 & 12 \\
\hline High school degree* & 9 & 20 \\
\hline Some high school & 9 & 6 \\
\hline Need help with dressing & I & 2 \\
\hline Need help with toileting & 2 & 4 \\
\hline Need help with transfers & 2 & 2 \\
\hline Need help with feeding & 0 & 1 \\
\hline Need help with shopping & 6 & 9 \\
\hline Need help preparing meals & 10 & 7 \\
\hline Need help with housekeeping & 10 & 8 \\
\hline Need help with laundry & 9 & 7 \\
\hline Need help with driving & 11 & 9 \\
\hline Need help with medications & 7 & 6 \\
\hline Need help with finances & 5 & 7 \\
\hline Perceived worsening health & 9 & 9 \\
\hline Perceived no change in health & 29 & 27 \\
\hline Perceived improving health & 12 & 14 \\
\hline No CPR order (by discharge) & 11 & 11 \\
\hline Underwent CPR & 0 & 0 \\
\hline Chose no ETI after interview & 16 & 17 \\
\hline Underwent intubation & 0 & 1 \\
\hline Average LOS (SD) & $4.4(2.83)$ & $4.5(4.9)$ \\
\hline Deaths & 2 & 3 \\
\hline
\end{tabular}

Note: *Statistically significant difference $(P<0.05)$.

Abbreviations: CPR, cardiopulmonary resuscitation; ETI, endotracheal intubation; LOS, length of stay. 
trajectory, or baseline understanding of CPR and intubation. There was no difference in patients refusing CPR or intubation in the script-only group $(11 / 50,22 \%)$ compared with the script+video group $(11 / 50,22 \%)$. No enrolled patients received CPR during admission, only one was intubated and similar numbers did not survive admission (two script vs. three script+video). When study patients were compared to 83 patients who declined participation, study patients were six times more likely $(22 / 100$ vs. $3 / 83)$ to have opted out of CPR and/or intubation.

\section{Discussion}

This study demonstrates that hospitalized elders who were willing to participate in this study of end-of-life decisionmaking, opted out of CPR at the same rate $(22 \%)$ whether or not they viewed a video depicting CPR and endotracheal intubation. While the video is not likely to harm efforts at informed consent for CPR, substantive, evidence-based, information-sharing may be the "effective" ingredient that could differentiate this from previous studies. ${ }^{1,3-6}$

Between 1992 and 2005, 433,985 Medicare beneficiaries underwent CPR in US hospitals. ${ }^{7}$ While roughly half may survive the initial cardiac arrest, many initial survivors go on to prolonged hospitalization including critical illness and only $18 \%$ (overall) survive to hospital discharge. Since survival of alive discharges at 1 year averages $59 \%,{ }^{8}$ overall survival at 1 year following CPR is $10.6 \%$. Not all of these patients are functionally independent and many have long-term (e.g., neurologic and other) sequelae. Outcomes following intubation are also not good. A landmark 2005 study estimated that more than 377,000 patients aged $\geq 65$ are mechanically ventilated each year. ${ }^{9}$ Of these, $25 \%-30 \%$ do not survive hospitalization and more than half of survivors are discharged to nursing homes, many with substantial physical and mental disabilities. ${ }^{10}$ These complex prognostic data must be considered in the context of specific patient health trajectory and values.

Withholding CPR requires informed consent from the patient; however if patients do not receive information and understand outcomes and prognosis of CPR, they are unable to provide informed consent. There is abundant evidence to suggest that many (if not a majority) of informed patients opt out. ${ }^{1-6}$ In a cohort of 371 non-hospitalized elderly patients ( $>60$ years), $41 \%$ opted for CPR before receiving information about it, which dropped to $22 \%$ after receiving prognostic statistics. ${ }^{1}$

Volandes et $\mathrm{al}^{4}$ randomized 50 patients with malignant brain tumors to receive either verbal narrative about CPR or narrative+video. "After the verbal description, 25.9\% of participants preferred life-prolonging care, $51.9 \%$ basic care, and $22.2 \%$ comfort care. In the video arm, no participants preferred life-prolonging care, $4.4 \%$ preferred basic care, 91.3\% preferred comfort care, and 4.4\% were uncertain." These results were reproduced in a cohort of 150 patients with advanced cancer; $48 \%$ of script-only patients opted for CPR while only $20 \%$ who received script+video opted for CPR. ${ }^{4}$ In a small study of 23 surrogate decision-makers of critically ill patients, script+video nearly doubled (41\% vs. $22 \%$ ) the rate at which surrogates opted out for their loved one. ${ }^{5}$ The same 3-minute video was deployed in a recent prospective randomized study of 150 elders with prognosis $<1$ year. Sixty-four percent of patients "treated" with videoassisted decision support opted out of CPR compared to only $32 \%$ receiving routine care. ${ }^{6}$ Our study differs in examining responses of acutely ill, hospitalized, non-terminally ill elders. Since ours was a heterogeneous group with varying prognosis, it is not surprising that the opt-out rate was substantially lower. Moreover, while our video included similar content, it was not professionally produced. So our findings suggest that either video (categorically) does not enhance decision-making or that the proprietary video used by Volandes et al adds, where our home-grown version (that includes similar content) does not. Interestingly, we demonstrated identical opt-out rates $(22 \%)$ in a pilot when we used the proprietary video. ${ }^{11} \mathrm{We}$ believe our data suggest that if verbal information-sharing is sufficient, the exact script or use of video is less consequential than systematic, early engagement of patients in shared decision-making. A recent review highlights paucity of studies to demonstrate definitive ideal approaches to these discussions, but concluded that "the most promising interventions involved structured discussion at the time of acute admission to hospital and review by specialist teams at the point of an acute deterioration" based largely on the results of one small study. ${ }^{12,13}$ Our observations support this conclusion, confirming that patients are willing to consider and make proactive, informed choices about their "code status."12,13

There are several limitations in our study. Firstly, the sample sizes were small and there were few in-hospital deaths, cardiopulmonary arrests or respiratory failure requiring endotracheal intubation. Secondly, many patients refused to participate in this study. Recruitment bias could overestimate the observed results if patients who preferred resuscitation systematically refused participation. Thirdly, our study does not necessarily demonstrate that the specific videos/script affected these results. We do not know what conversations occurred between patients who did not participate and their physicians. So, our result reflects the impact of a system- 
atic, uniform discussion about resuscitations rather than the specific impact of a script. Finally, end-of-life choices vary substantially among demographic groups, and while the study cohort is somewhat diverse, results represent choices at one hospital, in one city, in one region of the US that is not representative of all cities/regions/countries.

\section{Conclusion}

Our study suggests that if engaged early during hospital admission, with or without video assistance, a substantial proportion of hospitalized, non-critically ill elders opt out of CPR and intubation. Similar patients who were not uniformly engaged, opted out far less often. The interventions deployed in this study are practical, take little time to administer, and may serve as a useful complement for discussions with hospitalized patients about CPR/intubation. Our study confirms what previous surveys have suggested: that when informed of risks, benefits, and alternatives of CPR and intubation many patients opt out. ${ }^{1}$ Our study provides a simple, reproducible methodology that may promote patient autonomy through enhanced information-sharing.

\section{Disclosure}

The authors report no conflicts of interest in this work.

\section{References}

1. Murphy DJ, Burrows D, Santilli S, et al. The influence of the probability of survival on patients' preferences regarding cardiopulmonary resuscitation. N Engl J Med. 1994;330(8):545-549.
2. Mirza A, Kad R, Ellison NM. Cardiopulmonary resuscitation is not addressed in the admitting medical records for the majority of patients who undergo CPR in the hospital. Am J Hosp Palliat Care. 2005;22(1): $20-25$.

3. El-Jawahri A, Podgurski LM, Eichler AF, et al. Use of video to facilitate end-of-life discussions with patients with cancer: a randomized controlled trial. J Clin Oncol. 2010;28(2):305-310.

4. Volandes AE, Paasche-Orlow MK, Mitchell SL, et al. Randomized controlled trial of a video decision support tool for cardiopulmonary resuscitation decision making in advanced cancer. J Clin Oncol. 2013;31(3):380-386.

5. McCannon JB, O'Donell J, Thompson BT, et al. Augmenting communication and decision making in the intensive care unit with a cardiopulmonary resuscitation video decision support tool: a temporal intervention study. J Palliat Med. 2012;15(12):1382-1387.

6. El-Jawahri A, Mitchell SL, Paeche-Orlow MK, et al. A randomized controlled trial of a CPR and intubation video decision support tool for hospitalized patients. J Gen Intern Med. 2015;30(8):1071-1080.

7. Ehlenbach WJ, Barnato AE, Curtis JR, et al. Epidemiology of inhospital cardiopulmonary resuscitation in the elderly. $N$ Engl $J$ Med. 2009;361(1): 22-31.

8. Chan PS, Nallamouthu BK, Krumholz HM, et al. Long-term outcomes in elderly survivors of in-hospital cardiac arrest. $N$ Engl J Med. 2013;368(11):1019-1026.

9. Wunsch H, Linde-Zwirble WT, Angus DC, Hartman ME, Milbrandt EB, Kahn JM. The epidemiology of mechanical ventilation use in the United States. Crit Care Med. 2010;38(10):1947-1953.

10. Barnato AE, Albert SM, Angus DC, Lave JR, Degenholtz HB. Disability among elderly survivors of mechanical ventilation. Am J Respir Crit Care Med. 2011;183(8):1037-1042.

11. Naqvi I, Richardson-Royer CM, Riffel C, Harvey L, Manthous CA. A prospective randomized trial of informed consent for cardiopulmonary resuscitation. Am J Respir Crit Care Med. 2014;189: A3623.

12. Nicolasora N, Pannala R, Mountantonakis S, et al. If asked, hospitalized patients will choose whether to receive life-sustaining therapies. J Hosp Med. 2006;1(3):161-167.

13. Field RA, Fritz Z, Baker A, Grove A, Perkins GD. Systematic review of interventions to improve appropriate use and outcomes associated with do-not-attempt-cardiopulmonary-resuscitation decisions. Resuscitation. 2014;85(11):1418-1431. 


\section{Supplementary material}

Good morning/afternoon, I am Dr. (name) and I am working with Dr. Naqvi, here at the hospital, in a research study. The purpose is to see whether your choices about two treatments - called CPR and breathing machines - are affected by getting additional information about them. First, you'll watch a 3 minute film that shows these procedures and then l'll take about 5 minutes to explain more about risks, benefits and alternatives. We can stop at any time.

I have no reason to think you'll need it, but if your heart stops in the hospital, doctors can provide a procedure called CPR. CPR involves pushing on the chest and sometimes giving electric shocks to the chest to restart the heart. Usually medicines are given to restart the heart and breathing tube is always placed into the mouth and lungs to help breathing. Sometimes organs like the brain and kidneys can be harmed as a result of CPR. If the heart can be restarted, all patients go to intensive care on a breathing machine. 1 in 5 patients survive to leave the hospital after CPR. The alternative to CPR is to have a natural death without it. Do you have any questions? Would you want CPR or to be allowed a natural death?

Again, I have no reason to think you'll need it, but if you get breathing problems and can't speak for yourself, you can tell doctors now whether you'd want a breathing tube put into your mouth and lungs. The tube would be attached to a breathing machine that would help you breathe until doctors try to fix the problem. While some patients get better only 3 in 10 patients, age 65 or older, are alive a year later.

Breathing machines with tubes can also cause complications. One of 3 has difficulty with memory or thinking that can last 6 months after leaving. About 1 in 10 who survive has new physical weakness and 1 in 4 have either depression or stress. 1 in 10 elderly survivors are in nursing homes a year later. Do you have any questions or want me to repeat any of this information? If you developed difficulty breathing and the only choice is the breathing machine and tube or receiving medicines to ensure a comfortable death, which would you choose?

Figure SI Scripted intervention.

Note: Scripted intervention delivered to intervention groups in both pilot and final study. This script was analyzed using a web-based readability tool which indicates it is at between the $7^{\text {th }}$ and $8^{\text {th }}$ grade levels by the Coleman Liau and Automated Readability Indices.

Abbreviation: CPR, cardiopulmonary resuscitation.

International Journal of General Medicine

\section{Publish your work in this journal}

The International Journal of General Medicine is an international, peer-reviewed open-access journal that focuses on general and internal medicine, pathogenesis, epidemiology, diagnosis, monitoring and treatment protocols. The journal is characterized by the rapid reporting of reviews, original research and clinical studies across all disease areas.

\section{Dovepress}

The manuscript management system is completely online and includes a very quick and fair peer-review system, which is all easy to use. Visit http://www.dovepress.com/testimonials.php to read real quotes from published authors. 